Executive coaching - towards a dynamic alliance of psychotherapy and transformative learning processes

\author{
David E Gray \\ School of Management \\ University of Surrey
}

Accepted version (28 $8^{\text {th }}$ March 2005)

Published 2006 in:

Management Learning. 37(4) 475-497. 


\title{
Executive coaching - towards a dynamic alliance of psychotherapy and transformative learning processes
}

\begin{abstract}
Coaching is emerging as a major professional development and performance enhancement process for senior managers and executives. There are, however, few professional development programmes aimed specifically at coaches themselves, and no internationally recognised qualification or professional standard. Much of the literature on coaching has been written by practitioners or those with an interest in human psychology, and particularly psychotherapeutic approaches to support. Yet some psychotherapeutic processes sometimes assume quite longerterm relationships between the coach and the coachee - the 'therapeutic alliance'. Many businesses and managers themselves, however, usually seek focussed solutions to immediate problems. While recognising that there may be cases when longer-term relationships are entirely appropriate, this article offers adult learning theory, and specifically transformative learning, as an alternative or parallel theoretical model capable of underpinning the coaching processes. Transformative learning is concerned with the processes of critical reflection, the development of critical awareness of personal and organisational assumptions and the fostering of action. All coaches, however, need to be aware that the coaching process may open up deep-seated anxieties and problems, some of which are more appropriately addressed by a psychotherapeutic approach. Hence, a dynamic network model of coaching is proposed, in which psychotherapists and nontherapists collaborate to facilitate their mutual professional coaching development, learning and support.
\end{abstract}

Keywords: executive coaching, management learning, psychotherapy, adult learning theory, reflection, transformative learning, coaching networks. 


\section{Introduction}

Coaching is now emerging as one of the most significant approaches to the professional development of senior managers and executives. Much of the literature on coaching, however, brings with it an almost implicit assumption that, to the extent that coaching practice is underpinned by any theoretical model, this will be from a human psychology and particularly a psychotherapeutic perspective. While accepting that there will often be circumstances where the coaching intervention has to deal with managers who are experiencing deep seated problems, some of them of a personal nature, it is far from clear why coaching should necessarily so often adopt a psychotherapeutic approach. The purpose of this article is to evaluate the role of psychotherapy in coaching and to offer an alternative, or at least parallel, approach based upon adult learning theory. While there is no, single, model of adult learning theory, it is possible to identify in a number of theoretical perspectives, approaches that have been applied to adult learning but are here, uniquely, applied to coaching itself. Of particular interest is transformative learning theory and the concept of critical reflection whereby the coach seeks to foster in the coachee a deeper critical awareness of personal and organisational assumptions and to take action.

What is coaching?

The word 'coach' was first used in the $16^{\text {th }}$ century to describe a particular kind of carriage that conveyed people to where they wanted to be. In many senses, this idea of a journey towards a desired destination, sums up one of the goals of executive coaching today. Two decades ago, the concept of executive coaching was relatively unknown. Today, consultancy organisations offering coaching services to businesses are proliferating, encouraged by the growing number of organisations demanding their services. Indeed, Eggers and Clark (2000) report that executive coaching is the fastest growing area amongst consultancy companies and individual management consultants. A recent survey of $530 \mathrm{UK}$ organisations found that 78 per cent had made use of coaching (CIPD, 2004) and that coaching was the fastest growing approach to training delivery.

Yet, broad agreement on the goals of executive coaching is illusive. Downey refers to it as 'the art of facilitating the performance, learning and development of another' (2003: 15), while Whitmore links it to 'optimizing people's potential and performance (2002: 97). Carter (2001) defines executive coaching more broadly as 'a form of tailored work-related development for senior and professional managers which spans business, functional and personal skills' (Carter, 2001: 15). The International Coach Federation (a US-based professional body that represents personal and business coaches), however, also include development beyond the workplace. The ICF (2003), then, sees executive coaching as a process that is designed to help clients improve their learning and performance, and enhance their quality of life. The coached client is someone who wants to reach a higher level of performance, personal satisfaction or learning. In terms of relationship, the coach is not necessarily an 'expert' or 'authority' but someone who relates to the client in a spirit of partnership and collaboration. It is the client, however, who holds the ultimate responsibility for, and ownership of, the desired outcomes.

Executive coaching, however, is often confused with both mentoring and counselling and, to a lesser extent, with consultancy. Mentoring is a relationship, often internal within an organisation, whereby more experienced, often senior or executive managers, usually in the same speciality, provide support and a role model for less experience colleagues (Megginson and Clutterbuck, 1995). In terms of time, it is usually open-ended, and often associated with the mentee's career 
development and improved performance - although this is largely a UK focus, whereas in the USA mentoring has strong psychosocial and counselling elements (Gibb and Megginson, 1993). However, as Palmer (2003) points out, mentors can only draw upon their own experiences and are not necessarily trained to impart their knowledge. In the case of consultancy, consultants can survey a situation and come up with a set of strategies. With coaching, however, it is the coachees themselves who originate and commit to their own strategies, meaning that 'buy in' is more likely. Counselling, on the other hand, helps people to come to terms with the past, and provides support to, first contain, and then move out of a crisis. It is, essentially, remedial, helping someone to become 'whole' and to rediscover their place in the family, community or workplace and may be quite long term in duration. Some of the current models of coaching are similar to counselling in their supportive approach to the client and often in their attempts to locate deepseated, psychological causes to the client's problems. Furthermore, many coaches are counselling practitioners by profession (Hart et al. 2001).

Eggers and Clark (2000) note, however, that despite coaching moving swiftly into the mainstream of management development and training, there is a limited amount of literature available both in the academic journals and the popular press about this subject. Indeed, what is written, is often relatively narrow and pragmatic in focus, for example, a guide to 'how to coach' (Burdett, 1998), successful coaching interventions (Smith and Sandstrom, 1999; Paige, 2002; Olivero et al. 1997) or the characteristics of successful coaches (Hall et al., 1999). Within the literature there is also little consensus on what theoretical principles underpin executive coaching. As Eggers and Clark (2000) insist, if the coaching process starts with any underlying theory: 'this is usually firmly rooted in humanistic psychology or philosophy (whether the coach knows it or not)'. (p. 68) (My emphasis).

There seems to be an implicit suggestion here, then, that far from utilising specific theoretical models to underpin their practice, some coaches at least may only do this at a subconscious or at least tacit level. The assertion that executive coaching is rooted in humanistic psychology or philosophy is also worth exploring. Snyder (1995) notes, for example, that, whatever the focus of executive coaching, some coaches take a pragmatic, head-on approach to their client's business problems, while, in contrast, others use psychotherapeutic methods in an attempt to get to the deepseated roots of the client's difficulty. Hence, the purpose of this article is to examine the role of coaching in organisations, and especially how the use of psychological approaches informs the work of many coaching practitioners. The article also seeks to explore alternative approaches to coaching through adult learning theory which sees the manager, less as a patient or client, and more, at least potentially, as a problem-solving professional practitioner.

\section{The coaching role}

The most probable scenario for the future is not only that there will be perpetual change, but that the intensity of change will increase. Casey (1999), for example, points out that one feature of globalisation is the restructuring of labour markets, with high levels of geographical and occupational mobility and portfolio employment. Change, however, decreases our sense that we can depend on the world (Hudson, 1999). Complex change also affects people's abilities to sustain their motivation and commitment to long-term projects and even to the employing organisation itself. In this new environment of perpetual change, workers (and managers) cannot sustain these discontinuities in their lives and working environments, no matter how good their skills and leadership abilities, without support. In this sense, one of the roles of the coach is that 
of change agent. The coach helps to guide someone through a transient culture, including a transient corporate culture, helping people to become personally more confident, committed and able to sustain their drive and commitment. As change agents, coaches see change as an asset, not a threat. In Leadbeater's (2001) terms we must be authors of our work situation. At work we must be self-initiating, self-correcting and self-evaluating and the inventors of our own work (Kegan, 1994). 'Effective coaches model the future because they are willing to invent it, design it, and insist on it' (Hudson, 1999: 7).

This is one element in what Raelin (2000) calls the 'new learning', where the workplace itself is seen as the prime location for learning where people have to replace the idea of skill or competence learning with learning for 'meta competence' or learning to learn. Given the diverse nature of change within the workplace, it is not surprising that coaches can take on a variety of roles. Witherspoon and White (1996), for example, suggest four types of role:

- Coaching for skills, with a focus on specific skills required for a current job

- Coaching for performance, with a focus more broadly on a present job

- Coaching for development, focussed on learning for a future job

- Coaching for the executive's agenda, directed on learning related broadly to the executive's own interests

Each of these will now be examined in more detail.

Coaching for skills involves learning for a specific task or project, with 'skill' being defined broadly as learning basic concepts, strategies, methods, behaviours, attitudes and perspectives for business success. Sometimes the executive may be completely unfamiliar with a concept or skill and at other times may only need remedial learning or sharpening of ideas. Initial analysis of the manager's current skills level may involve direct observation of the learner within the work setting (Caplan, 2003). In contrast to other coaching roles, coaching for skills usually involves high levels of clarity in terms of the client (and often his or her organisation) being quite specific about the goals to be achieved. Coaching for skills can be effective for learning on the job or where job redesign means the introduction of new job roles and responsibilities. The coaching for skills relationship is usually a relatively short one, taking place over days or weeks, with executives being in a position to implement their new skills quickly. In a survey, Judge and Cowell (1997) found that the most common request from clients was attaining help in modifying their interaction styles and building trust in their working relationships.

Coaching for performance provides a focus on the executive's present job role and seeks to make the executive more effective. Sometimes this may comprise remedial action, seeking to change problematic behaviours. But often the definition of what performances need addressing is less clear, with the coach and the executive working towards a shared agreement on goals and outcomes. Hence, the coach may work with the executive to assess performance, to obtain feedback from direct reports, peers or line managers on strengths and weaknesses. In terms of timescales, coaching for performance may take place over several months.

Coaching for development typically focuses on an executive's future job or career. Some coaches specialise in this area, calling themselves 'career coaches'. Key skills and attributes are identified, particularly in the areas of leadership, but clear and specific goals may be limited or lacking before consensus can be reached. But one of the contradictions of leadership is that the leadership behaviours that are associated with previous success, may not be the behaviours that are needed to 
achieve tomorrow's innovation (Goldsmith, 2003). For example, managers note their successes and assume that these are all due to the ways in which they manage and operate. But they do not realise that they are successful because of some behaviours and in spite of others. Successful people also tend to over-commit themselves and to over-rate their performance in relation to the ratings given by their peers. Hence, one facet of executive coaching for development may be helping successful managers to unlearn their previously successful behaviours in order to adopt new ones.

Coaching for the executive's agenda can involve a very broad range of issues. Witherspoon and White (1996) suggest that these often include productivity and quality improvement, mergers and acquisitions, coping with growth and change management. Leadership can be a lonely activity, so having someone from outside the organisation can be useful in providing support and constructive feedback. Thach and Heinselman (1999) mention the examples of global marketing, finance or operations for a specific industry as being typical of the kinds of subject knowledge an executive might require. Other important skills included dealing better with change and improving public speaking skills.

There are, therefore, a range of roles the executive coach can play. However, precisely how the executive coach performs these roles will depend, at least in part, on the theoretical perspectives that underpin their practice. It is therefore to some of these epistemological questions that we now turn.

\section{Executive coaching through psychotherapy}

The theoretical framework of executive coaching, currently, draws heavily upon the principles and processes of psychotherapy (Judge and Cowell, 1997). Hart et al. (2001) also claim that coaching and therapy are both based on similar theoretical constructs. This is because the psychotherapeutic perspective gets clients to freely discuss difficult personal issues, and to explore 'blind spots', biases and shortcomings in order to gain new perspectives and insights. Many coaching interventions are preceded by an assessment of the coachee's psychological profile. It is quite common, for example, for coaching practitioners to make use of the MyersBriggs Type Indicator, an instrument based closely upon a Jungian psychodynamic model. For coaches, psychotherapy encourages a commitment to confidentiality and adopting an ethical stance, to providing feedback, to establishing strong boundaries between personal and professional relationships, and to supporting and challenging the coachees.

Williams et al (2002) support this view, arguing that pure skills-based coaching seldom achieves the results of long-term change. Sustainable change seems to require that the client recognises the deep motivators that underlie his or her behaviour. This 'in-depth' approach looks at the client holistically, not just in terms of work role, but also his or her personal history and current personal life - the 'alignment of head and heart' (Williams et al, 2002: 121). Psychological testing is used to assess the client's effectiveness and to understand internal motivators - beliefs, emotions and unconscious assumptions. Interviews may be conducted with the client's friends and family (spouse, parents, siblings, teenage children) exploring family relationships and early family history. This psychotherapeutic approach is in sharp contrast to skills building which may be reticent about delving into the client's personal or emotional life.

The oldest of the psychotherapies, the Freudian approach, posits that behaviour is the result of the interplay of conflicting internal forces. The theory is dynamic in the sense that, when two forces 
come into conflict a third and different force is produced. Put at its most simple, human psychic energy is expressed through three channels: the id (the pleasure principle); the ego, which is reality orientated and pragmatic, its main function being to control the id yet still satisfy needs; and the superego, the moral channel, whose goal is the ideal, rather than the real, and which strives for perfection. The superego subdues the impulses of the id and tries to substitute moralistic goals for realistic ones. An important element of psychodynamic theory is fantasy. In a workplace setting, for example, we may become enmeshed in fantasies about our career aspirations and build an idealised notion of who and what we are in the organisational hierarchy (the 'ego ideal'). But in practice, few are able to realise these hopes so they may begin to experience psychic conflict or even hostile and aggressive impulses.

One of Freud's enduring legacies has been the way he shows how we come to protect our ego and sense of self. For example, we may use a variety of defence mechanisms to deny or distort reality so that we find situations less threatening. These defence mechanisms often protect us in the short term but are self-defeating in the end. With one kind of defence mechanism, sublimation, for example, uncomfortable emotional energy is channelled into activity which is socially acceptable. Rather than face this discomfort, the employee 'gets busy', redirecting their energy towards positive goals. In the case of another defence mechanism, substitution, instead of undertaking a threatening task, we work on a comfortable one (Peltier, 2001) - for example, avoiding writing that difficult business plan by answering yesterday's emails.

In recent years, alternative branches of psychotherapy have developed, many of which are practised by executive coaches. Many of these (for example, person-centred psychotherapy, gestalt psychotherapy and neuro-linguistic programming) are branches of humanistic psychotherapy which began its growth to prominence during the 1950s and 1960s. In contrast to those schools of thought which see human beings as subject to sexually or biologically driven impulses, humanistic psychotherapy takes a constructive view, stressing peoples' independent dignity, worth, and capacity to develop personal competence and self-respect. Rogers (2003), one of the founding fathers of the humanistic psychotherapy movement, saw person-centred therapy as a means by which the therapist offers personal congruence, empathetic understanding and unconditional positive regard to the client. Facilitators must show a caring and respect for the learner which includes empathetic listening and trust. It is a co-learning relationship (Rogers and Freiberg, 1994), not dissimilar to the collaborative learning journey taken by coach and client.

Gestalt is essentially a 'third force psychology', that is, a grouping which does not originate in either a Freudian or Pavlovian tradition (Clarkson, 1989). Some of the essential components of the Gestalt approach include developing a dialogical relationship between the counsellor (or coach) and client, observing processes and developing diagnostic perspectives from them. In line with an approach which stresses pattern and the whole form, Gestalt sees all the tasks and skills involved as interwoven and impossible to understand in isolation from each other. So when a counsellor (or coach) first meets a client, there may be a focus on the need to develop rapport and to clarify client needs (attending to beginnings). But at the same time the counsellor may be observing the client's processes of contacting with the environment and be formulating some initial diagnostic hypotheses. Each of these tasks may be revisited in a spiralling and recursive loop. This may include attending to and exploring processes in the client's background to identify life themes and patterns (Mackewn, 1997).

Another branch of humanistic psychotherapy, neuro-linguistic programming (NLP) is possibly even more prevalent in the coaching community. NLP is grounded on the belief that individuals 
actively construct their own versions of 'reality', based upon their personal experiences. Hence, the same events can mean different things to different people. This is partly because people have different ways of selecting and recording information. One of the basic principles of NLP is that all of the senses used here can be improved and developed so that a person's personal goals can be enriched. NLP coaches use a variety of tools when working with clients. Through 'modelling', for example, the coachee can be encouraged to model a person's skill not only by observing them in action, but by close questioning to gain an insight into their attitude and what they are thinking when performing the act. Motivation may be stimulated through the use of 'compelling futures' where the client is asked to make a representation in their minds of a future state or experience for example, imagining shaking hands on a successful business deal. While in the early stages, an individual may benefit from working with a coach, one of the objectives is that they will begin to understand their own processes and issues and begin to coach themselves (McDermott and Jago: 2001).

Another therapeutic approach, cognitive behavioural therapy (CBT) recognises unconscious processes, but defines them differently and accords them a less central role in influencing behaviour. The central tenet of CBT is that thoughts mediate between a stimulus or event and our emotions. In other words, it is not the external event that determines the emotional response, but someone's interpretation of the event. Hence, coaches who practice CBT will help individuals to identify and to dispute the negative thoughts and beliefs they have about themselves. This often means the learning of new skills, monitoring personal trains of thought, identifying beliefs and subjecting themselves to the laws of reason.

Judge and Cowell (1997) suggest, however, that there are important differences between the executive coaching process and traditional psychotherapy. Firstly, they argue that the coaching contract is usually predefined and relatively short term in duration. This, they claim, means that there is usually insufficient time to develop a 'therapeutic alliance' so important in some traditional psychotherapeutic approaches, the coaching relationship being more akin to that of a 'developmental partnership'. Secondly, coaching contains more of a systems focus than traditional psychotherapy, with often the involvement of not just the client, but also managers, peers, subordinates and even spouses. Hence, the dynamics of the client-coach relationship are necessarily different, particularly on issues such as ethics and confidentiality. Thirdly, coaching focuses on a particular area - in the case of executive coaching, management and leadership whilst psychotherapy is less context-specific. Sperry (1993) also notes the potentially limited role of psychotherapy in executive coaching, arguing that psychotherapy involves the executive in a close, collaborative relationship that may require longer-term therapy. The natural inclination of many executives for pragmatism and action may mean that they find such interventions frustrating and tedious. According to Levinson (1996) the coach must be: 'Authoritative with respect to the psychological and coaching processes and also authoritative in his or her knowledge of the business world' (Levinson, 1996: 115). (my emphasis). Hence, even if the coach was able to engage the coachee therapeutically, it may also be necessary to provide business-specific skills and knowledge.

Goodman (2002) also warns that coaches need to be orientated to business strategy and to understand the complexities of organisations: Coaches who 'overemphasis personal enlightenment will ultimately undermine a coaching program'. (Goodman, 2002: 197). Hodgetts (2002) also cautions that organisations must distinguish between coaching and psychotherapy. He concedes that both approaches aim at behavioural change and to help individuals understand that 
their cognitive and emotional reactions may interfere with personal effectiveness. The goal of coaching, however, is to improve the person's effectiveness at work in ways that are linked to overall business strategy. Saporito (1996) agrees, stating that the efforts of coaches need to be intimately tied to the realities of the business. While therapy explores non-work elements of an individual's life, that may include the client's childhood, relationships with parents and other family members, this may be less appropriate for an executive coach:

When organizations fail to draw the line between therapy and coaching, they leave the door open for coaches, especially those with clinical training and backgrounds, to practice therapy at the company's expense, with potentially negative consequences. (Hodgetts, 2002: 215)

Hodgetts (2002) warns that other problems may present themselves. Firstly, the coach that becomes too therapeutic may lengthen the coaching process and hence the costs of coaching for the organisation. Secondly, therapeutic coaching may leave coachees emotionally vulnerable in ways that might actually hinder their professional efficiency. Thirdly, coaching that becomes too therapeutic may actually divert attention from the focus on important work-related issues. Therapeutic coaching may also leave the organisation vulnerable to legal risks if the coaching intervention ends badly.

It may be mistaken, however, to identify all psychotherapeutic approaches as long term, unsystematic and lacking in focus. As O'Connell (2003) shows, solution-focused therapy (sometimes called brief, solution-based therapy (Dielman, 1998)), with its emphasis on getting clients to work with the therapist to identify solutions (not to hark on past problems) may produce quick resolutions (depending on the depth of the problem). Therapists and clients work together in a collaborative relationship, where clients are encouraged to identify any small steps they have taken that helped towards a solution. This includes changes in behaviour, attitudes, or emotions. The task of the therapist is seen as 'raising clients' awareness of the constructive solutions already in their lives and to help them to find ways to expand upon them' (O'Connell, 2003: 5). There is an emphasis on the agreement and setting of achievable goals, linked to the client's preferred outcomes. It is a structured approach in which clearly identified stages are moved through, including problem-free talk (on subjects not linked at all to the central problem), goal setting, exception seeking (when the problem is not present) and competence seeking (finding and acknowledging their own resources and strengths).

Hence, while some of the critiques of psychotherapy may have some substance, they ignore some of the vital contributions this approach may make to coaching - some of which has been suggested above. Nevertheless, there are other alternative approaches to coaching that have a more direct, learning and problem-solving focus. This article discusses one such example, transformative learning, before going on to explore how coaching may be able to combine both therapy and problem-based learning in one, dynamic alliance.

\section{Coaching and theories of adult learning}

Adult learning theory (or theories, since it is arguable whether any unified theory of adult learning exists), offers a useful underpinning to coaching practice because it emphasises the selfdetermination, self-actualisation and self-transformation of the learner (Jarvis, et al, 1998). It was Knowles (1975) who introduced the term 'andragogy' (in contrast to pedagogy) to describe approaches to the teaching of adult learners. Hence, learners are viewed as autonomous 
individuals (self-directed learners) who have control of, and responsibility for, their own learning. The learning climate is one in which learners must feel valued and supported, and involved in the self-evaluation of their own learning (Knowles, 1975). Learning itself is experiential. People working alongside such learners in a 'teaching' capacity do not approach this task from the viewpoint of instruction, but in terms of facilitation and constructive dialogue. Hence, according to Jarvis et al (1998) the role of the 'teacher' could be to:

- Provide information on certain topics

- Serve as a resource for the individual

- Assist learners to assess their needs and competencies

- Locate resources or secure new information

- Set up learning experiences

- Work with learners as a sounding board for ideas

- Help learners to develop an positive attitude towards learning and self-directed inquiry

In a sense, many of the roles list above could be said to mirror those of the coach.

It was Dewey (1938) who first put forward the idea that learning was concerned with experience rather than just the acquisition of abstract knowledge. In recent years, experiential learning theory has become quite central to understanding how adults learn, including learning in the workplace (Marsick, 1987). Throughout their lives, adults accumulate a wide range of experiences which are stored in their memories, and which are recalled in order to interpret new experiences. According to Jarvis (1987) learning is the process of transforming present experience into knowledge, skills, attitudes, values and emotions which, in turn, modify the individual biography of the learner. This learning is both primary, through direct experiences, and secondary, through linguistic communication - for example, through an event or experience being described to the learner by someone else.

Jarvis (1995), however, also argues that experience does not inevitably lead to learning but must include non-learning, non-reflective learning as well as reflective learning. Non-learning is a common phenomenon because it is often a response to everyday experience. Part of human experience is to build up a mental model of the structure of the world. As long as experiences conform to this structure, mental models remain unmodified and no learning is required. Although Jarvis (1995) does not discuss the role of coaches specifically, is could be suggested that their task might be to minimise the danger of non-learning by challenging the validity of a client's perception that an experience is merely a familiar one. Particularly with some work routines, for example, there may be a tendency for the learner to assume too quickly that an event is familiar, without first critically reflecting on what might be different or new (non-reflective learning). The opportunity for learning is lost. Jarvis (1995) also refers to this as non-consideration where people are often too busy to think about an experience or too fearful of its outcomes or consequences. People may also fail to learn because they simply refuse to change their mind-sets, such as a situation where someone holds, either consciously or unconsciously, strong antiinclusive beliefs. Clearly, this is an area that a coach might want to challenge.

While Jarvis (1995) is right to point out how events can be fail to promote reflection (and hence learning), many other commentators have been more optimistic about the outcomes of reflection. However, a precise definition of reflection has been open to many different interpretations. One 
of the earliest models was that developed by Kolb and Fry (1975) in which reflection was one element of a learning cycle which comprised: concrete experience, observations and reflections, abstract conceptualisation and generalisations, active experimentation. Unfortunately, as Boud et al (1985a) point out, the Kolb model does not discuss reflection in much detail.

The work of Schön has been highly influential in throwing light on the nature of professional knowledge (including the knowledge of managers) and the process of learning in organisations, and the significance of learning within changing societies. Schön distinguishes between 'technical rationality' which is taught didactically - usually through academic institutions - and 'theories-in-use' which are unique to the individual and developed through professional practice (Schön, 1992). For Schön, it is the 'theories-in-use' that deserve to be placed in higher regard. Hallett (1997), however, differs from Schön arguing that within reflective practice and coaching there is a role for 'technical rationality', that is, the use of academic theories. While such theories do not necessarily help practitioners in the early stages of 'knowing-in-action', they can play an important role at later stages when the practitioner is able to draw links between the two.

McGonagill describes reflection-in-action as a form of artistry, in which practitioners frame problems, devise and experiment with solutions and reframe as 'the situations talk back' (2002: 60). There is a sense, of course, in which coaches can (indeed, should) become reflective practitioners themselves through:

- Displaying an awareness of their own filters for making meaning of learning interactions.

- Becoming consciously aware of their own assumptions, methods and tools.

- Regarding each client as a fresh challenge to models that are continuously in evolution.

Reflection-in-action itself can be facilitated through coaching. Here, Schön (1987) identifies three approaches to the process. The first, joint experimentation, is a process by which the student and coach work together, often through a process of discussion, debate and dialogue. Some experiments might be purely exploratory, with actions taken only to see what follows. Others might be move-testing, performed in order to initiate a change. Thirdly, hypothesis-testing experiments where a hypothesis is either confirmed or disconfirmed as a result of action. Where a practitioner reflects-in-action in a situation which he perceives as unique, where he surfaces his intuitive understanding of the phenomenon, his experiment is at the same time exploratory, move-testing and hypothesis testing. But the primary goal of experimentation is action and change. Reflection-in-action plays a central part in experimentation (Schön, 1991). Typical approaches include what Schön calls 'Follow me!' and 'Hall of Mirrors'.

In Follow me! the student learns by following the example or performance of the coach, although the extent to which the coach acts as a role model can be made either explicit or left implicit in their actions. Through Follow me! the student can try to enter the coach's world view, follow a coach's instructions or observe and emulate a coach's actions (note the similarity between this and modelling in NLP). In all cases, the coach can reciprocate by providing feedback on the student's efforts, although one of the dangers of Follow me! is its potential for triggering the learner's defences, especially where their own performance is deemed sub-standard.

Hall of Mirrors is described in relation to the teaching and learning of psychotherapy and demonstrates the interactions between a supervisor (coach) and student (client). The coaching session itself is used to 'mirror' the student's psychotherapy sessions with their own clients in order to resolve problems. In doing this, the student's framing of situations can be made visible 
and raised as an object for discussion and public reflection. An explicit awareness of how the student has framed a problem is the first stage for the task of reframing it. The supervisor/coach not only allows the student/client to observe the kinds of actions they might carry out with their own clients (as in Follow me!), but also experience what it feels like to be on the receiving end of the action. Hence, a coach may help towards developing the coaching skills of a manager, particularly since many managers are now required to coach their team - guiding them strategically or helping specific task performance (Whetten and Cameron, 2005). So through the Hall of Mirrors process, a manager can both experience coaching, and learn to reflect on what it might feel like for their subordinates to be coached by him or her. Clearly, the manager's own coach can guide this reflective process. As Biegun (2003) points out, the coach can also demonstrate the skills and processes of being a reflective-practitioner - providing a model for meaning making both for the client and the coach.

Although conceived with teachers in mind, Boud et al (1985b) describe a model of reflection that offers valuable guidance to coaches. Reflection itself is conceptualised as a person's response to experience, either through an external event or perhaps through an internal experience arising out of a discomfort with one's present state. But to be effective, reflection must be a conscious process. 'It is only when we bring our ideas to our consciousness that we can evaluate them and begin to make choices about what we will and will not do' (p. 19). This conscious reflective process can be promoted and aided, either through individual reflective processes (such as through keeping a diary), by group discussion, or through debriefing by an individual. For learning to emerge from experience, scheduled time must be put aside for this process (as would be arranged for a coaching session). During these reflective sessions, the learner must be encouraged to work through three stages, namely:

- Stage 1: Returning to the experience to recollect events (replaying events in the mind's eye), recollect feelings about the events, but (with the help of a facilitator) avoid making judgements.

- Stage 2: Attending to feelings. Positive feelings in particular can provide an impetus to persist in challenging situations, and can help to see events more sharply. Negative feelings can block new learning. The expression of feelings needs to be within a supportive environment (which facilitators can provide).

- Stage 3: Re-evaluating the experience. A number of processes are involved here: association, that is, relating the experience to that which is already known; integration, looking for relationships in the data; validation, the checking of the new data against existing knowledge and beliefs; appropriation, where validated knowledge becomes part of the person's value system. (Here the facilitator has an important role in helping the learner to clarify constructs, offer support and provide criteria for performance for new goals.)

The outcomes of reflection may be the clarification of an issue, the development of a new skill, or the resolution of a problem. But the benefits of reflection will be lost if they are not linked back into action. Hence, the learner must make a commitment of some kind on the basis of the new learning (as in the action points that may be agreed at the conclusion of a coaching session). This idea of reflection leading to action is an essential element of the transformative learning model, to which we now turn.

Adult learning in action - Transformative learning 
While there are numerous models and interpretations of adult learning, in recent years Mezirow's concept of transformative learning has taken centre stage (Elkins, 2003). Transformative learning is defined by Mezirow its originator as: 'The social process of construing and appropriating a new or revised interpretation of the meaning of one's experience as a guide to action' (Mezirow, 1994: 222 - 223). According to Cranton, transformative learning theory has taken adult learning theory 'beyond andragogy' (1992:17). This is, in part, because transformative learning theory sees the educator as taking responsibility for fostering critical self-reflection and helping learners to then take action. The educator, then, acts as a kind of 'empathetic provocateur' (Cranton, 1992: 17). It also means acting as a role model for critical reflection and also as a committed co-learner. Rather than knowing the learner's experiences and using them as a resource for discussion, the educator comes to encourage a critical examination of these experiences and the assumptions that underlie them - a process aimed at transforming the learner's meaning perspectives. Transformation is not complete without the learner acting on the basis of their new learning. It is this emphasis on encouraging self-reflection on fostering action and on co-learning that makes transformative learning a potentially powerful guide to coaching - and coaching a powerful tool for generating transformative learning.

Allee (1997) argues that the transformative learning process is capable of producing dramatic and sweeping changes in individuals. Tosey and Mathison agree, arguing that transformative learning is capable of 'reaching a kind of renewed, deeper awareness, a reconfiguring and reintegrating world view (2003: 1). Newman (1994) argues that within transformative learning the concept of reflection is of a different order to Schön's because it aims to achieve a form of meta-reflection where we not only see the world and ourselves more clearly, we see ourselves seeing the world. In other words, we perceive our perceptions and we are aware of our awareness. We become aware of our psychological and cultural (and organisational) assumptions which constrain the way in which we relate to others and the way in which we live our lives - including our working lives. It is a form of reflection that: 'Permits us to see that our views, our identity, even apparently incontrovertible facts, are generated and constructed; and it allows us to examine the form, the nature and the validity of those constructions'. (Newman, 1994: 239).

The most personally significant transformations occur when we are able to critique the premises (perspectives) we hold about ourselves (Mezirow, 1996). Human beings create meanings out of their everyday experiences and act, or at least try to act, in accord with these meanings (Pohland and Bova, 2000). While meaning schemes are points of view that can become transformed by everyday insights, perspectives are 'obdurate, less permeable, and more elusive habits of mind (Mezirow, 1996: 168). This, of course, is where coaching may play a vital role. Transformative learning argues that, because we are trapped by our own meaning perspectives, we can never make interpretations of our experience free from bias. Hence, we need to expose our ideas to rational and reflective discourse by turning to those who are best informed and who can offer a critical assessment of the evidence and arrive consensually at the best judgement - a form of validity testing. As an 'objective' outsider, the coach, of course, is ideally placed to do this. Critical reflection is not an integral part of the immediate 'call to action'. A pause is required during which one's meaning perspectives are re-examined - as happens in the iterative coaching process.

One feature that makes transformative learning theory so applicable to coaching in workplace environments is that it sees the most significant learning arising from critical reflection on premises about oneself (Taylor, 2001). Mezirow (1991) argues that the following phases have 
been identified through empirical studies as having resonance for critical self-reflection (which, it is argued here, coaches may assist and promote, particularly in workplace settings):

- A disorienting dilemma

- A critical assessment of assumptions

- Recognition that one's discontent and the process of transformation are shared, and that others have negotiated a similar change

- Exploring options for new roles, relationships and actions

- Planning a course of action

- Acquiring knowledge and skills for implementing one's plans

- Renegotiating relationships and negotiating new relationships

- Building competence and self-confidence in new roles and relationships

The process of critical reflection, however, involves a search for meaning that is shaped and delimited by our frames of reference. These comprise two meaning structures. One involves meaning perspectives which include sociolinguistic codes (social norms, ideologies, language games, theories, etc), psychological codes (personality traits, repressed parental prohibitions which block our ways of feeling and acting) and epistemic codes (learning styles, sensory learning preferences, etc.). Some of these perspectives are acquired through cultural assimilation, some are stereotypes that are unintentionally learned (such as what it means to be a 'manager', or 'executive') and others may be intentionally learned (such as through coaching).

The other meaning structure involves meaning schemes which are more specific manifestations of meaning perspectives and include concepts, beliefs, judgements and feelings which shape our interpretations. These meaning schemes provide us with the rules for interpreting (Mezirow, 1990). When events occur that collide with our meaning structures, this triggers a process of reflection which comprises a critique of our assumptions (their origins, nature and consequences) to examine whether our beliefs remain functional. So, for example, being overlooked for promotion may force a manager to re-evaluate his performance and feelings of self-worth.

According to Mezirow (1994), most reflection takes place within the context of problem-solving when we reflect on the content of the problem, the process of problem-solving or the underlying premise of the problem. These processes mean that workplace learners must have the freedom and flexibility to advance their beliefs, explanations, assess evidence and be empathetic to the perspectives of others. Often, through a process of action research, learners can collaborate with others to evaluate the context of management ideas and the belief systems that shape these perspectives (Mezirow, 1997). This must also include organisational belief systems and cultures. According to Elkins (1997) these key traits generated through transformative learning can easily translate into management and leadership competencies.

Another element of transformative learning that has significance for learning in workplace environments (through, for example, coaching), is the distinction drawn between instrumental learning (learning to control and manipulate the environment) and communicative learning. Instrumental learning involves problem solving and learning from experience. While shop floor employees have always had to do this, it is only in recent years that attention has been paid to how managers and professionals learn in this way (Marsick, 1990). While Mezirow (1991, 1994, 1996) discusses transformative learning in the context of education and teaching, we could just as 
easily say that:

Education (coaching) for competence involves cultivating the learner's (coachee's) ability to negotiate meanings and purposes instead of passively accepting the social realities defined by others. (Mezirow, 1994: 226) (words in brackets added)

Educators (coaches) can facilitate reflective action by helping their clients overcome situational, knowledge or emotional constraints. It means helping the coachee to progress towards a capacity to fully participate in rational dialogue and to achieve a 'broader, more discriminating, permeable and integrative understanding of his/her experience as a guide to action' (Mezirow, 1994: 226).

Goodman (2002) argues that leading-edge organisations need to dedicate themselves to transformational learning - learning that not only addresses knowledge (content and information) but the critical, thinking processes that underpin the continuous acquisition and processing of knowledge. Such critical thinking can be facilitated by what Goodman terms a developmental coaching dialogue which helps to encourage adult thinking capacities towards increased complexity. The developmental coaching dialogue is informed by constructivist-developmental psychology which postulates that human beings actively build or make meaning from their experiences, both independently and through their inter-relationships with others. People also develop through increasingly complex orders of consciousness, each order building on the previous ones. The coaching dialogue seeks to create a milieu to transform a client's thinking and behaviour through a mixture of support (helping clients take risks) and challenge (providing the push that encourages change). The plans that emerge from a constructivist-developmental perspective require that any proposed change must be at a level appropriate to the client's developmental level, creating some disequilibrium in the client's thinking, but not so much that confidence and motivation are threatened.

Unfortunately, as Taylor (1997) notes, there is a paucity of empirical research into the connection between critical reflection and transformative learning. One exception is the heuristic study by Carter (2002) who investigated the learning that emerges in professional developmental relationships amongst a group of mid-career women managers. Conducted through the use of interviews and journals (completed by both the researcher and the 10 participants acting as coresearchers), the study found that conversations with work colleagues, bosses, friends and family members, as well as internal dialogue, can contribute to transformative learning. In contrast to some of Mezirow's (1991) assumptions that such learning occurs through rational dialogue, the women in this study used dialogue that was highly personal and self-disclosing. When undertaken in an atmosphere of safety and trust, these dialogues helped the women reach deeper levels of understanding than could be found on just an analytical plane. Significantly, the women paid scant attention to developmental relationships and communication as learning strategies until these factors were brought to their conscious awareness through dialogue and journal-keeping as part of the research process. It is possible that journals could be important tools for assisting transformative learning within the coaching process.

Carter's (2002) study also raises the issue of whether gender differences require consideration in the coaching and transformative learning process. In their study of 135 college women, Belenky et al (1986) found that many lacked a confident, sustained, 'inner voice'. They learned by listening, with knowledge seen as received, rather than constructed. By trying to please others (including institutional authority), there was little sense of an authentic voice or space for the growth of self, even though this plays a central role in transformations in women's ways of 
knowing. It is essential, then, to help women to develop their own authentic voices, and allow time for the knowledge that emerges from first hand experiences, rather than formal, 'out of context' learning. Coaching, of course, is capable of helping people to connect with these experiences. Coaches, however, may need to be sensitive to some of the different ways in which women 'know' and seek to develop their inner voice.

\section{Towards a Dynamic coaching model}

Currently, many executive coaches come from a psychotherapeutic background and may be professional counsellors, or may have a portfolio that contains both coachees and counselling clients. There are reasons to believe, however, that the use of some psychotherapeutic techniques may not always be appropriate for coaching in business settings. As has been argued, some counselling models, for example, can involve longer-term relationships (the therapeutic alliance), whereas organisations often prefer shorter-term relationships with more specifically defined goals and outcomes. Indeed, the natural inclination of managers for action and pragmatism may make them emotionally disinclined towards therapeutic relationships (Judge and Cowell, 1997). Organisations, too, may need to use therapy with caution, especially if the therapeutic relationship goes wrong and the organisation opens itself up to legal action (Hodgetts, 2002). Yet, the negative behaviours demonstrated by a manager may be the product of deepseated problems. Even managers who suffer at the level of 'emotional overload' can sometimes benefit from therapeutic help.

Hart et al. (2001) also warn that coaches who lack a professional therapeutic background need to watch out for 'red flag' dangers that they may be unable to handle. The first are the indicators of deeper client issues including depression, anxiety attacks, alcohol or drug abuse, personality disorders or paranoia. The signs to watch out for are low effectiveness, high degrees of chaos and the inability to take action. Other flags include persistent anger or aggression, self-destructive impulses and extreme dependency. Coaches who have not trained as therapists may have blind spots themselves, in that their personal paradigms mean they approach everyone as whole or complete - sometimes missing pathological behaviour. Indeed, coaches may show their own pathology of unresolved issues!

Is it possible, then, for the strengths of therapeutic coaches and adult learning or business coaches to be combined? Is it possible to create a dynamic, synergistic coaching model? The rest of this article demonstrates how, through bringing together coaches from diverse theoretical backgrounds and practices, a coaching network can facilitate and promote mutual understanding, support and personal growth. This is achieved through the network promoting the professional development of its members.

Drawing coaches from diverse professional backgrounds, a coaching network can provide an excellent informal forum simply for the provision of advice and mutual support. Figure 1, offers an example of such a network which combines the membership of both psychotherapeutic coaches (Gestalt and NLP coaches are used here for illustration) with coaches with a transformative learning approach, as well as a more performance/skills-based business coaching background. One potential benefit of this kind of network is that it could give access to therapeutic coaches in dealing with potentially dangerous 'red flag' issues (Hart et al, 2001). This could comprise advice or even referral.

But above all, these networks could facilitate the mutual learning of all coaches through 
continuous professional development (CPD). CPD involves taking time for personal reflection and review (Megginson and Whitaker, 2003). Coaching networks, particularly if they meet on a scheduled basis, can use these opportunities to exchange ideas on alterative coaching tools and techniques, and to discuss and learn from critical incidents in coaching. Critical incidents are described by Tripp (1993) as an interpretation of the significance of an event. They are analysed as critical when they are indicative of significant underlying structures, motives or trends. At first, many events appear to be 'the norm' rather than 'critical'. However, it is the process of reflective analysis which enables them to be classified as being critical. One of the strengths of operating through a dynamic coaching network is that events such as critical incidents can be analysed from different standpoints. Therapeutic coaches, for example, will tend to explore such incidents for promoting self-knowledge and as catalysts for personal change (Roehlke, 1988). Transformative learning coaches will see such incidents as opportunities for critical reflection and the transformation of meaning perspectives. While this may include an analysis of psychological codes (including parental prohibitions) it also includes broader sociolinguistic codes (which include social norms, theories and language games) and a critique of organisational belief systems and cultures. Hence, transformative learning involves a reflection on perspectives that goes beyond the individual and psychological.

\section{Figure 1 Informal coaching network}

Another area where dynamic networks can facilitate collaboration is in the field of ethics. In psychotherapy there is a long tradition of adherence to ethical standards. Therapists undertake courses in ethics as part of their professional training and are members of professional 
associations that have strict ethical codes. As Peltier (2001) points out, coaches from nontherapeutic backgrounds, (which includes transformative learning coaches) may not always be members of professional associations that possess a written ethical code. But even therapists may suffer from ethical conflicts when acting as coaches. As therapists, they have a duty of care to their patient or client. Coaching in the business world, however, is performed within the context of organisations with fairly unambiguous competitive and profit motivation. Coaches, then, may be faced by situations of conflicting loyalty - on the one hand a duty to the organisational sponsor and business, but on the other hand a duty of care to the coachee. Indeed, one of the challenges is often in being able to accurately identify who the client actually $i s$ - the individual or his/her sponsoring organisation? As Peltier argues, what may be needed here are 'doses of collegial consultation (Peltier, 2001: 223). This, potentially, is what the dynamic coaching network offers.

Finally, another area where the dynamic network can play a role is in the process of coaching supervision (see Figure 2). Currently, within the professional practice of coaching, anecdotal evidence suggests that many non-therapeutic coaches are unsupervised, or at best undertake supervision on a sporadic basis. In contrast, coaches from a counselling or psychotherapeutic background have a long tradition of supervision, both as part of their initial professional training and then as an ongoing process of updating (Ronnestad and Skovholt, 1993). Figure 2, then, offers a model of supervision in this case provided by a coach from a psychotherapeutic background. According to Greben (1985) there is a similarity between the processes that occur in psychotherapy generally and those that take place in supervision. Both, for example, emphasise mutuality in respectful engagement and teamwork - the supervisory working alliance (Bordin, 1983). Supervision may also involve a modelling process where the supervisee observes the supervisor in the process of professional practice (Stoltenberg, 1993). Ronnestad and Skovholt (1993) also discuss the experience therapists have in negotiating an explicit contract between supervisor and supervisee, in terms of development needs, supervisor goals and methods and opportunities for personal growth. Contract negotiation, for example, is an important process in transactional analysis (Lapworth, Sills and Fish, 1993) and so is another potential contribution of psychotherapeutic approaches to the dynamic coaching network. However, whether supervision should be conducted by therapists or practitioners from other professional backgrounds requires further evaluation and research. 


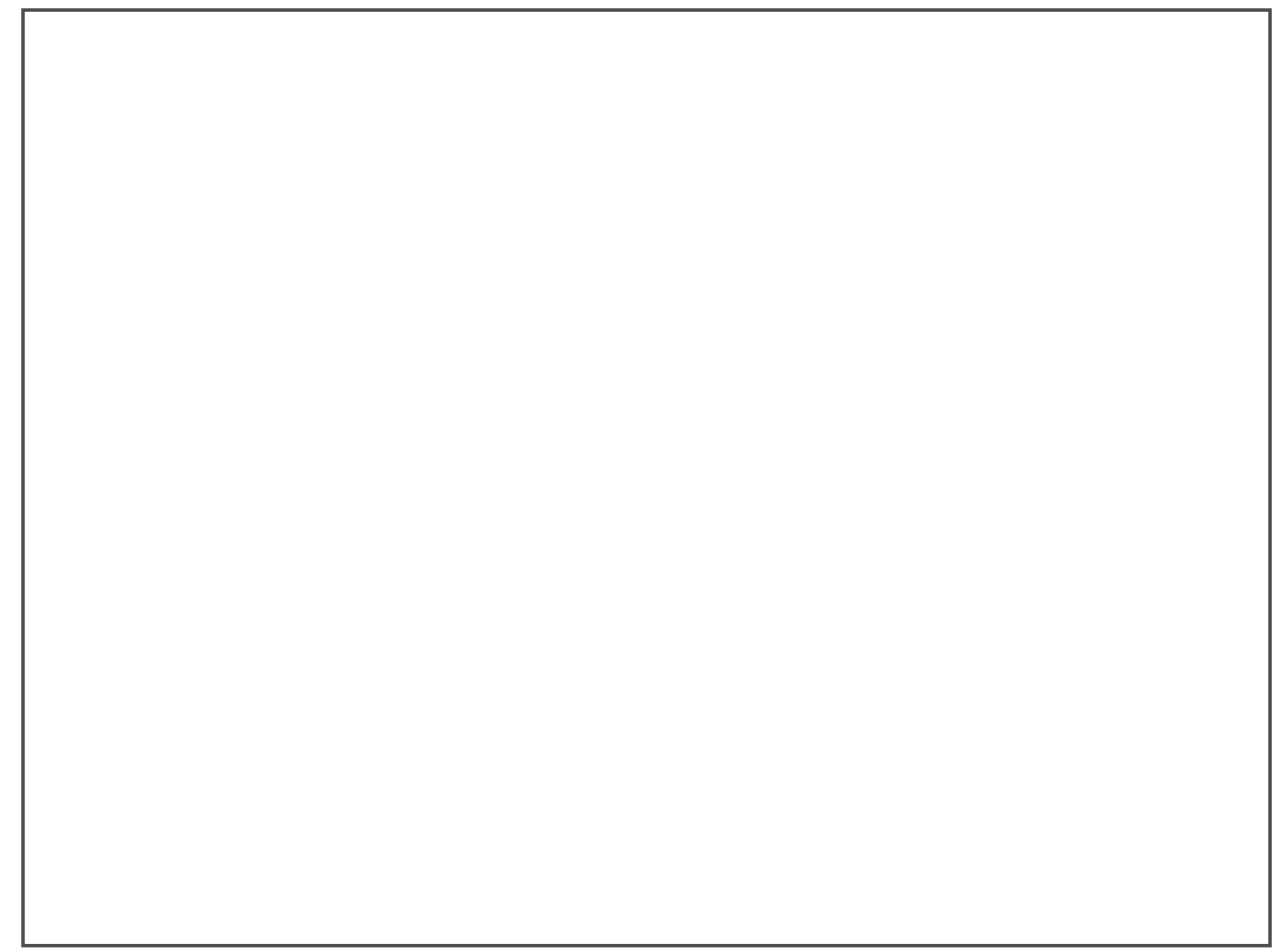

Figure 2 Dynamic coaching network

In the final analysis, the style and paradigm adopted by coaches needs to be linked to the goals of the client (the organisational sponsor) and to the needs of the coachee. The process of coaching using critical reflective approaches such as transformative learning, can yield dynamic growth in a manager's thinking capacity, judgement and decision-making. But it is acknowledged that the coaching process is a complex journey where the actual final destination is often unknown, the road is dark, and there are no maps. Coaches may wittingly or unwittingly open up a coachee's deep-seated psychological anxieties. Coaches not trained in psychotherapy, then, must be sensitive to 'red flags' and know if or when it is time to refer a coachee on to a professional psychotherapist. This process is facilitated if coaches work together in coaching networks. The concept of the dynamic coaching network accords a central, supervisory role to the coach with psychotherapeutic knowledge and accreditation. It is recognised, however, that coaching is made stronger by combining the many coaching paradigms. Through the dynamic coaching network, coaches from different professional perspectives come together to share knowledge, offer mutual support and develop their professional practise. It takes coaching beyond the therapeutic alliance, into a new alliance amongst coaches themselves.

Word count $=9022$ 


\section{References}

Allee, V. (1997 'Transformational Learning’ Executive Excellence 14 (8) 12.

Belenky, M.F., Clinchy, B.M., Goldberger, N.R. \& Tarule, J.M. (1986) Women's Ways of Knowing: The Development of Self, Voice and Mind Basic Books.

Bordin, E.S. (1983) 'A working alliance based model of supervision'. The Counseling Psychologist 11 35-41.

Boud, D., Keogh, R. and Walker, D. (1985a) 'What is Reflection in Learning' in Boud, D., Keogh, R. and Walker, D. Reflection: Turning Experience into Learning London: Kogan Page.

Boud, D., Keogh, R. and Walker, D. (1985b) 'Promoting Reflection in Learning: a Model' in Boud, D., Keogh, R. and Walker, D. Reflection: Turning Experience into Learning London: Kogan Page.

Boud, D (1999). Understanding Learning at Work London: Routledge.

Burdett, J.O. (1998) 'Forty things every manager should know about coaching' Journal of Management Development 17 (2) 142-152.

Brunner, R. (1998) 'Psychoanalysis and coaching' Journal of Managerial Psychology. 13 (7) 515-517.

Caplan, J. Coaching for the Future: How smart companies use coaching and mentoring London: CIPD.

Carter, A. (2001) Executive Coaching: Inspiring Performance at Work Brighton: The Institute for Employment Studies.

Carter, T.J. (2002) 'The Importance of Talk to Midcareer Women's Development: A Collaborative Inquiry' The Journal of Business Communication 39 (1) 55-91.

Casey, C. (1999) 'The changing contexts of work' in Boud, D. Understanding Learning at Work London: Routledge.

CIPD (2004) Training and development 2004: Survey report London: Chartered Institute of Personnel and Development.

Clarkson, P. (1989) Gestalt Counselling in Action London: Sage.

Cranton, P. A. (1992) Working with Adult Learners Toronto: Wall \& Emerson, Inc.

Dewey, J. (1938) Experience and Education New York: Macmillan.

Dielman, Marc B (1998) 'Brief solution-focused therapy with parents and adolescents with ADHD.' Social Work in Education 20 261-268 October.

Downey, M. (2003) Effective Coaching London: Texere.

Eggers, J.H. and Clark, D. (2000) 'Executive coaching that wins' Ivey Business Journal Sept/Oct.

Elkins, S.L. (2003) 'Transformational Learning in Leadership and Management Positions' Human Resource Development Quarterly 14 (2) 351-358. 
Fitzgerald, C. and Berger, G.J. (eds.) (2002) Executive Coaching: Practices and Perspectives Palo Alto, CA: Davies-Black Publishing

Gibb, S. and Megginson, D. (1993) 'Inside corporate mentoring schemes: a new agenda of concerns.' Personnel Review 22 (1) 40 - 54.

Goldsmith, M. (2003) 'Helping successful people get even better'. Business Strategy Review 14 (1) 9-16.

Goodman, R.G. (2002) 'Coaching Senior Executives for Effective Business Leadership: The Use of Adult Development Theory as a Basis for Transformational Change' in Fitzgerald, C. and Berger, G.J. eds) Executive Coaching: Practices and Perspectives Palo Alto, CA: DaviesBlack Publishing.

Greben, S.E. (1985) 'Dear Brutus: Dealing with unresponsiveness through supervision. Canadian Journal of Psychiatry 30 48-53.

Hall, D.T., Otazo, K.L. and Hollenbeck, G.P. (1999) 'Behind Closed Doors: What Really Happens in Executive Coaching' Organizational Dynamics Winter.

Hart, V, Blattner, J. and Leipsic (2001) 'Coaching Versus Therapy: A Perspective' Consulting Psychotherapy Journal: Practice and Research 53 (4) 229-237.

Hodgetts, W.H. (2002) 'Using Executive Coaching in Organizations: What Can Go Wrong (and How to Prevent it) in Fitzgerald, C. and Berger, G.J. eds) Executive Coaching: Practices and Perspectives Palo Alto, CA: Davies-Black Publishing.

Hudson, F.M. (1999) The Handbook of Coaching San Francisco: Jossey-Bass Publishers.

ICF (2003) International Coach Federation.

http://www.coachfederation.org/aboutcoaching/nature.htm (Accessed 14 April).

Jarvis, P. (1987) Adult Learning in the Social Context London: Croom Helm.

Jarvis, P. (1995) Adult and Continuing Education $2^{\text {nd }}$ ed. London: Routledge.

Jarvis, P., Holford, J. and Griffin, C. (1998) The Theory and Practice of Learning London: Kogan Page.

Judge, W.Q. and Cowell, J. (1997) 'The Brave New World of Executive Coaching' Business Horizons 4 (40).

Kegan, R. (1994) In Over Our Heads: The Mental Demands of Modern Life Cambridge, MA: Harvard University Press.

Knowles, M. (1975) Self-Directed Learning: a guide for learners and teachers New York: Associated Press.

Lapworth, P., Sills, C. \& Fish, S. (1993) Transactional Analysis Counselling Bicester: Winslow Press.

Leadbeater, D (2001) 'Learning and work - authorship' in CIPD The Future of Learning at Work London: CIPD.

Levinson, H. (1996) 'Executive Coaching' Consulting Psychology Journal 48 (2) 115 - 126.

Mackewn, J. (1997) Developing Gestalt Counselling: A field theoretical and relational model of contemporary Gestalt counselling and psychotherapy London: Sage. 
Marsick, V (1987) (ed.) Learning in the Workplace London: Croom Helm.

Marsick, V (1990) 'Action Learning and Reflection in the Workplace' in Mezirow, J. ed Fostering Critical Reflection in Adulthood San Francisco: CA: Jossey-Bass.

McDermott, I. and Jago, W. (2001) The NLP Coach London: Piatkus.

McGonagill, G. (2002) 'The Coach as Reflective Practitioner: Notes from a Journey without End' in Fitzgerald, C. and Berger, G.J. eds Executive Coaching: Practices and Perspectives Palo Alto, CA: Davies-Black Publishing.

Megginson, D. and Clutterbuck, D. (1995) Mentoring in action: a practical guide for managers London: Kogan Page.

Megginson, D. and Whitaker, V. (2003) Continuous Professional Development London: CIPD.

Mezirow, J. (1990). 'How Critical Reflection Triggers Transformative Learning' in Mezirow, J. ed Fostering Critical Reflection in Adulthood: A Guide to Transformative and Emancipatory Learning San Francisco, CA: Jossey-Bass Publishers.

Mezirow, J. (1990) ed Fostering Critical Reflection in Adulthood San Francisco: CA: JosseyBass.

Mezirow, J. (1991) Transformative Dimensions of Adult Learning San Francisco: CA: JosseyBass.

Mezirow, J. (1994) 'Understanding Transformation Theory' in Adult Education Quarterly 44 (4) $222-223$.

Mezirow, J. (1996) 'Contemporary Paradigms of Learning' in Adult Education Quarterly 46 (3) $158-173$.

Mezirow, J. (1997) 'Transformative Learning: Theory to Practice' in Cranton, P. (ed) Transformative Learning in Action: Insights from Practice San Francisco, CA: Jossey-Bass.

O'Connell, B (2003) 'Introduction to the Solution-Focused Approach' in O'Connell, B. and Palmer, S. eds. Handbook of Solution-Focused Therapy London: Sage.

Paige, H. (2002) 'Examining the Effectiveness of Executive Coaching on Executives'. International Education Journal 3 (2) 61-70.

Palmer, B. (2003) 'Maximizing value from executive coaching' Strategic HR Review 2 (6) 2629.

Peltier, B. (2001) The Psychology of Executive Coaching: Theory and Application New York: Brunner-Routledge.

Pohland, P. and Bova, B. (2000) 'Professional development as transformational learning' International Journal of Leadership in Education 3 (2) 137 - 150.

Raelin, J. (2000) Work-Based Learning: The New Frontiers of Management Development New Jersey: Prentice Hall.

Roehlke, H.J. (1988) 'Critical Incidents in Counselor Development: Examples of Jung's Concept of Synchronicity'. Journal of Counseling and Development 67 October 133-134.

Rogers, C. and Freiberg, H.J. (1994) Freedom to Learn New Jersey: Prentice Hall. 
Ronnestad, M.H. \& Skovholt, T.M. (1993) 'Supervision of Beginning and Advanced Graduate Students of Counseling and Psychotherapy' Journal of Counseling \& Development March/April 71 396-405.

Saporito, T.J. (1996) 'Business-Linked Executive Development: Coaching Senior Executives' Consulting Psychology Journal: Practice and Research 48 (2) 96-103.

Schön, D. A. (1983) The Reflective Practitioner London: Temple Smith.

Schön, D. A. (1987) Educating the Reflective Practitioner San Francisco: Jossey-Bass Publishers.

Schön, D. A. (1991) The Reflective Practitioner: How Professionals Think in Action. Aldershot: Ashgate Publishing Ltd.

Smith, L. and Sandstrom, J. ((1999) 'Executive leader coaching as a strategic activity' Strategy Leadership 27 (6) 33-36.

Snyder, A. (1995) 'Executive Coaching: The New Solution’ Management Review 84 (3) 29-32.

Sperry, L. (1993) 'Working With Executives: Consulting, Counselling and Coaching'. Individual Psychology 49 (2) 257-266.

Stoltenberg, C.D. (1993) 'Supervising Consultants in Training: An Application of a Model of Supervision’ Journal of Counseling \& Development November/December 72 131-138.

Taylor, E.W. (1997) 'Building upon the theoretical debate: A critical review of the empirical studies of Mezirow's transformative learning theory' Adult Education Quarterly 48 (1) 34-59.

Taylor, E.W. (2001) 'Transformational learning theory: a neurobiological perspective of the role of emotions and unconscious ways of knowing' International Journal of Lifelong Education 20 (3) $218-236$.

Thach, L. and Heinselman, T. (1999) 'Executive Coaching Defined' Training and Development, March.

Tosey, P. and Mathison, J. (2003) 'Mapping Transformative Learning: a Neurolinguistic Programming Perspective' Conference paper - Living Sprit: New Dimensions in Work and Learning University of Surrey July 2003.

Tripp, D. (1993) Critical Incidents in Teaching: Developing Professional Judgement London: Routledge.

Vygotsky, L.S. (1978) Mind in society Cambridge, MA: Harvard University Press.

Whetten, D.A. \& Cameron, K.S. (2005) Developing Management Skills $6^{\text {th }}$ ed. New Jersey: Pearson Education International.

Whitmore, J. (2002) Coaching for Performance $3^{\text {rd }}$ ed. London: Nicholas Brealey

Williams, K., Kiel, F., Doyle, M. and Singara, L. (2002) 'Breaking the boundaries: Leveraging the Personal in Executive Coaching' in Fitzgerald, C. and Berger, G.J. eds Executive Coaching: Practices and Perspectives Palo Alto, CA: Davies-Black Publishing.

Witherspoon, R. and White, R.P. (1996) 'Executive Coaching: A Continuum of Roles'. Consulting Psychology Journal: Practice and Research Spring 124 - 133. 